\title{
Leucine-rich G Protein-coupled Receptor-5 Is Significantly Increased in the Aqueous Humor of Human Eye with Proliferative Diabetic Retinopathy
}

\author{
Eun Hee Hong ${ }^{1 \dagger}$, Mina Hwang ${ }^{2 \dagger}$, Yong Un Shin ${ }^{1}$, Hyun-Hee Park ${ }^{2}$, \\ Seong-Ho $\mathrm{Koh}^{2 *}$ and Heeyoon $\mathrm{Cho}^{1 *}$ \\ ${ }^{1}$ Department of Ophthalmology, Hanyang University College of Medicine, Seoul 04763, Korea, \\ ${ }^{2}$ Department of Neurology, Hanyang University College of Medicine, Seoul 04763, Korea
}

\begin{abstract}
Leucine-rich G protein-coupled receptor-5 (LGR5) is known to be a stem cell marker in many organs. LGR5 may have important roles in proliferative diabetic retinopathy (PDR) because LGR5 potentiate the Wnt/ $\beta$-catenin pathway, which plays crucial roles in pathologic neovascularization in the retina. The association between LGR5 and retinal pathologic neovascularization has not yet been reported. In the present study, LGR5 was compared in human aqueous humor $(\mathrm{AH})$ between normal control and patients with PDR to confirm the relationship between LGR5 and PDR. AH was collected from 7 naïve PDR patients and 3 control subjects before intravitreal injection and cataract surgery, respectively. LGR5 and key members of Wnt/ $\beta$-catenin were assessed by western blotting. In the present study, it was confirmed for the first time that LGR5 is detected in AH and it increases in PDR patients. Key members of Wnt/ $\beta$-catenin pathway were also increased in AH of PDR patients compared to control. These findings might support the hypothesis that LGR5 has important roles in PDR especially considering the roles of the Wnt/ $\beta$-catenin pathway, which is activated by LGR5, contributing to retinal pathologic neovascularization.
\end{abstract}

Key words: Leucine-rich G protein-coupled receptor-5, Aqueous humor, Pathologic neovascularization, Diabetic retinopathy, Wnt signaling pathway

\section{INTRODUCTION}

Leucine-rich G protein-coupled receptor-5 (LGR5), also known as GPR49, was initially cloned as an orphan receptor and identi-

Received April 13,2018, Revised June 8, 2018,

Accepted June 21,2018

* To whom correspondence should be addressed.

Heeyoon Cho, TEL: 82-31-560-2350, FAX: 82-31-551-6267

e-mail:hycho@hanyang.ac.kr

Seong-Ho Koh, TEL: 82-31-560-2260, FAX: 82-31-560-2267

e-mail:ksh213@hanyang.ac.kr

These authors contributed equally. fied as a member of the leucine-rich repeat-containing G proteincoupled receptor (LGR) family [1,2]. LGR5 was primarily known as a marker of self-renewing stem cells in rapidly proliferating epithelia under physiological conditions or upon injury, including the stomach [3], small intestine, colon [4], and so on [5-10]. In the visual system, it has been reported that LGR5 was detected in only two ocular tissues: the cornea in human [11-13] and the retina in mouse. LGR5 expressing retinal amacrine cells of mouse retina were the first piece of evidence that LGR5 was also expressed in neuronal but not stem cell lineage [14, 15], and were known to possess regenerative capacity and function as an endogenous regenerative source in adult mice [14]. However, so far there have
Copyright $\odot$ Experimental Neurobiology 2018. www.enjournal.org
This is an Open Access article distributed under the terms of the Creative Commons Attribution Non-Commercial License (http://creativecommons.org/licenses/by-nc/4.0) which permits unrestricted non-commercial use, distribution, and reproduction in any medium, provided the original work is properly cited. 
been no human studies regarding LGR5 in retina.

Wnt $/ \beta$-catenin signaling pathway has been known to play crucial role not only in developmental retinal angiogenesis but also pathologic neovascularization $[16,17]$. As LGR5 stabilizes Wnt receptor Frizzled (FZD) and potentiates the Wnt/ $\beta$-catenin pathway $[18,19]$, LGR5 likely contributes to retinal pathologic neovascularization. The association between LGR5 and retinal pathologic neovascularization has not yet been reported. In the present study, we investigated whether LGR5 can be detected in aqueous humor $(\mathrm{AH})$ as a novel marker of pathologic neovascularization. In addition, LGR5 level was compared in AH between normal control and proliferative diabetic retinopathy (PDR).

\section{MATERIALS AND METHODS}

This prospective cross-sectional study included normal subjects and PDR patients who visited Retina Clinic of the Department of Ophthalmology of Hanyang University Guri Hospital between January 2017 and May 2017. The study protocol was reviewed and approved by the Institutional Review Board of Hanyang University Guri Hospital (IRB FILE No. 2017-03-002) and adhered to the tenets of the Declaration of Helsinki. All participants provided written, informed consent to participation in the study.

A total of 10 subjects, 7 naïve PDR patients (PDR group) and 3 control subjects who were scheduled for intravitreal injection and cataract surgery, respectively, were recruited for this study. Inclusion criteria for the PDR group were treatment-naïve PDR, no diabetic macular edema on optical coherence tomography (OCT), no history of previous panretinal photocoagulation, intravitreal injection of any agent, and previous pars plana vitrectomy, and no history of co-existent macular pathology and had a sufficiently deep anterior chamber to perform anterior chamber paracentesis without complications. AH was also collected during cataract surgery from normal subjects who met the inclusion criteria as follows: no history of ocular diseases other than cataract, no prior intraocular surgery, no use of any topical ocular medications other than topical mydriatic and antibiotic prior to surgery, and no systemic diseases other than hypertension. Additionally, subjects in both groups were excluded if they were receiving renal dialysis or systemic immunosuppression at any time during the study or had a history of stroke or myocardial infarction or if the amount of AH sample collected was not sufficient for analysis or was judged as inappropriate for analysis. All participants underwent standard ophthalmologic examination including best-corrected visual acuity, intraocular pressure, slit lamp biomicroscopy, OCT (Swept Source OCT, Topcon DRI OCT-1 Atlantis; Topcon, Inc., Tokyo, Japan), and Optos ultra-wide fundus photography (FP) and fluo- rescein angiography (FA, Optos, Dunfermline, Scotland). The diagnosis of PDR was made when new vessels appeared in the FA. AH samples were collected by the same operator at the beginning of the procedure (surgery or injection). Briefly, after placing a sterile eyelid speculum, $1 \sim 2$ drops of $0.5 \%$ proparacaine hydrochloride (Alcaine, Alcon, Ft. Worth, TX, USA) and 5\% povidone iodine were instilled immediately before surgery or injection. Anterior chamber paracentesis was performed using a 30-gauge needle mounted on a $1 \mathrm{~mL}$ tuberculin syringe inserted through the peripheral cornea under the surgical microscope, and approximately 50 200 $\mu \mathrm{L}$ of AH was collected. AH samples were transferred to tubes and immediately placed on dry ice. Samples were stored at $-80^{\circ} \mathrm{C}$ until further processing. First, the AH LGR5 levels were analyzed in seven PDR patients and three control subjects by western blotting. For further analysis, we grouped the AH of five PDR patients and five control subjects and used the mixture of each group to analyze the levels of other wnt signaling pathway proteins by western blotting.

Levels of LGR5 and key members of the Wnt/ $\beta$-catenin signaling pathway in the AH were analyzed by western blotting. To remove impurities, the $\mathrm{AH}$ was centrifuged at 10,000 rpm for $5 \mathrm{~min}$, and the supernatant was incubated in protease inhibitor solution [1 $\mathrm{mM}$ phenylmethylsulfonylfluoride (PMSF), $1 \mathrm{mM}$ sodium fluoride $(\mathrm{NaF}), 1 \mathrm{mM}$ sodium orthovanadate $\left(\mathrm{Na}_{3} \mathrm{VO}_{4}\right), 100 \mathrm{X}$ protease inhibitor] for $30 \mathrm{~min}$ on ice. The $\mathrm{AH}$ was sonicated with a Sonoplus (Bandelin Electronics, Berlin, Germany) and incubated for $30 \mathrm{~min}$ on ice again. The sonicated AH were centrifuged at 13,000 rpm for $15 \mathrm{~min}$ and the supernatant was collected. Protein concentrations of AH lysates were determined using a Bio-Rad (Hercules, CA, USA) protein assay kit. Next, $0.1 \mu \mathrm{g}$ of LGR5 positive control protein (R\&D Systems, Minneapolis, MN, USA) and AH samples containing equal amounts $(25 \mu \mathrm{g})$ of protein were resolved by $4 \sim 12 \%$ sodium dodecyl sulfate-polyacrylamide gel (Invitrogen, Carlsbad, CA, USA) electrophoresis and then transferred to polyvinylidene fluoride membranes (Millipore, Billerica, MA, USA). Membranes were blocked with $2 \%$ skim milk and incubated with a specific primary antibody. The following antibody was used in these experiments: anti-LGR5 (1:200, Santa Cruz Biotechnologies, Santa Cruz, CA, USA), anti-R-spondin 1 ( $1 \mu \mathrm{g} / \mathrm{ml}$, R\&D systems), anti-active $\beta$-catenin (1:1000, Cell Signaling, Beverly, MA, USA), anti-phospho-GSK3 $\beta$ (1:100, Cell Signaling), anti-GSK3 $\beta$ (1:500, Cell Signaling), anti-cyclin D1 (1:2000, Cell Signaling), anti-c-myc (1:1000, Cell Signaling), anti-VEGF (1:1000, Abcam, Burlingame, CA, USA). Membranes were washed with Tris-buffered saline containing $0.1 \%$ Tween-20 and processed using the appropriate horseradish peroxidase-conjugated anti-mouse antibody (Jackson ImmunoResearch Laboratories, Inc., West Grove, PA, USA), anti- 
rabbit antibody (1:2000, Jackson ImmunoResearch Laboratories, Inc.), or anti-goat antibody (1:2000, Jackson ImmunoResearch Laboratories, Inc.) followed by ECL detection (GenDEPOT, Katy, TX, USA). Blots were quantified with an image analyzer (ImageQuant LAS 4000; GE Healthcare, Little Chalfont, UK).

\section{RESULTS AND DISCUSSION}

Table 1 shows the patient characteristics and ophthalmic data. The mean age of the control group and PDR group were $65.0 \pm 2.6$ and $46.0 \pm 13.1$ years, respectively. Three control subjects (case 1 3) had no systemic disease and no ocular disease except for cataract. Among PDR patients (case 4 10), two patients had neovascular glaucoma due to PDR (case 4 and 7), while two patients showed vitreous hemorrhage due to PDR (case 6 and 7). Wide FPs and wide FAs in each of two cases in PDR and control group are shown in Fig. 1. Among PDR patients, case 5 (Fig. 1A, B), and HRPDR patient, case 8 (Fig. 1C, D), showed retinal hemorrhage and microvascular abnormalities and case 8 showed hard exudates, extensive nonperfusion area, severe ischemia with retinal neovascularization

Table 1. Patient characteristics and ophthalmic data of control and diabetic retinopathy patients (e.g., a, b, etc.)

\begin{tabular}{|c|c|c|c|c|c|c|c|c|c|c|}
\hline & $\mathbf{M} / \mathbf{F}$ & Age & Diagnosis & Laterality & Underlying diseases & BCVA & IOP & SE & CMT & HbAlc \\
\hline \multicolumn{11}{|c|}{ Control } \\
\hline 1 & $\mathrm{~F}$ & 66 & Control & OD & $(-)$ & 0.4 & 20 & err & $\mathrm{n} / \mathrm{c}$ & $\mathrm{n} / \mathrm{c}$ \\
\hline 2 & M & 62 & Control & OD & $(-)$ & 1 & 13 & 1 & 228 & $\mathrm{n} / \mathrm{c}$ \\
\hline 3 & $\mathrm{~F}$ & 67 & Control & OD & $(-)$ & 0.3 & 13 & 0 & $\mathrm{n} / \mathrm{c}$ & $\mathrm{n} / \mathrm{c}$ \\
\hline \multicolumn{11}{|l|}{ PDR } \\
\hline 4 & M & 50 & NVG, HRPDR & OS & DM, HTN, CKD & 0.5 & 19 & -2.5 & 210 & 6.6 \\
\hline 5 & M & 56 & PDR & OD & DM, HTN, CKD & 0.5 & 15 & -1.75 & 232 & 8.4 \\
\hline 6 & M & 62 & HRPDR,VH & OD & DM, HTN, CKD & 0.15 & 17 & 0 & 280 & 7.7 \\
\hline 7 & M & 33 & NVG, HRPDR, VH & OS & $\mathrm{DM}$ & $\mathrm{FC} 30 \mathrm{~cm}$ & 62 & -2.75 & 224 & 8.4 \\
\hline 8 & M & 25 & HRPDR & OD & $\mathrm{DM}$ & 0.04 & 17 & err & $\mathrm{n} / \mathrm{c}^{\mathrm{a}}$ & 13.1 \\
\hline 9 & $\mathrm{~F}$ & 44 & HRPDR & OS & DM, HTN, CKD & 0.2 & 20 & -2.25 & 263 & 11.7 \\
\hline 10 & $\mathrm{~F}$ & 52 & HRPDR & OS & DM, HTN, CKD & $\mathrm{FC} 40 \mathrm{~cm}$ & 16 & -1.25 & 265 & 7.3 \\
\hline
\end{tabular}

${ }^{a}$ Not checkable due to premacular hemorrhage.

BCVA, best corrected visual acuity; CKD, Chronic kidney disease; CMT, central macular thickness; DM, diabetes mellitus; DME, diabetic macular edema; HbAlc, hemoglobin Alc; HRPDR, high risk proliferative diabetic retinopathy; HTN, hypertension; IOP, intraocular pressure; NVG, neovascular glaucoma; PDR, proliferative diabetic retinopathy; $\mathrm{SE}$, spherical equivalent; $\mathrm{VH}$, vitreous hemorrhage.

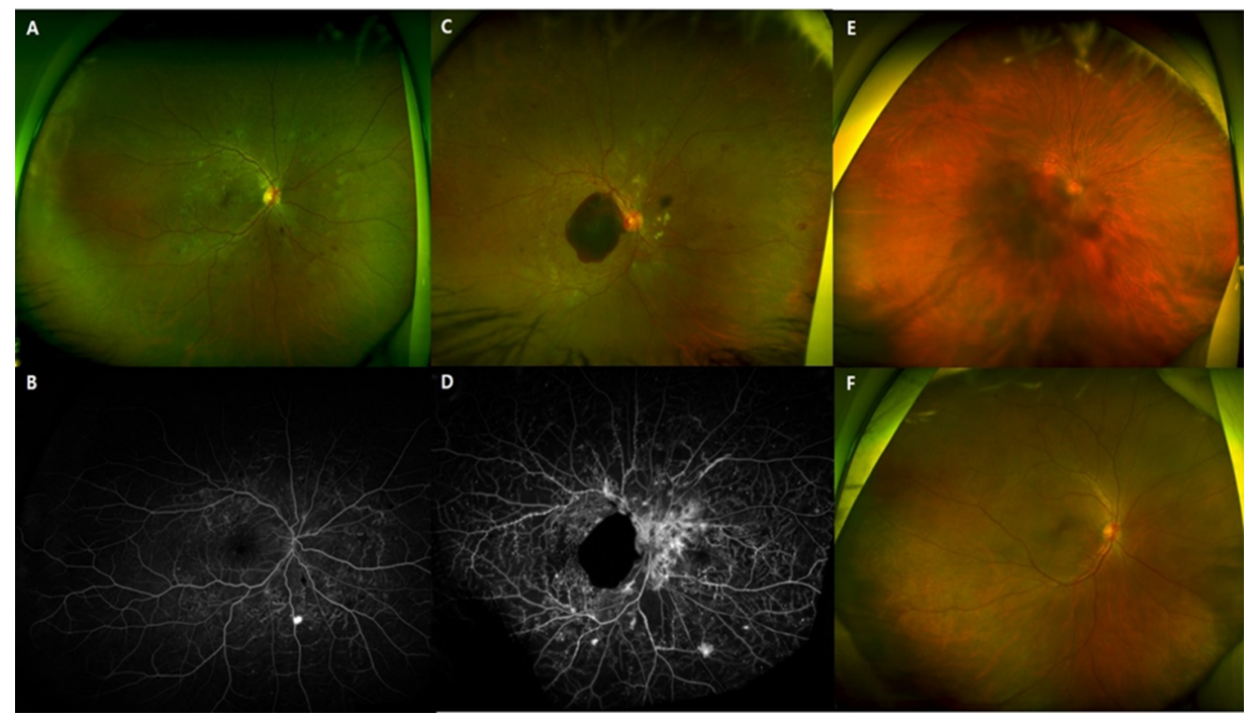

Fig. 1. Wide fluorescein angiography (FA) and wide fundus photographic findings of proliferative diabetic retinopathy (PDR) and control cases. (A, B) Wide fundus photograph and wide FA of case 5 (PDR) patients showed microvascular abnormalities, retinal hemorrhage, and limited retinal neovascularization (NV). (C, D) Wide fundus photograph and wide FA of case 8 (high-risk PDR) show retinal hemorrhage, hard exudates, extensive nonperfusion area, severe ischemia with retinal NVs, and premacular hemorrhage. (E, F) Wide fundus photographs of control cases (E, case 1; F, case 3) showed normal findings except for media opacity. 
$(\mathrm{NV})$, and premacular hemorrhage in wide FPs (Fig. 1A, case 5; Fig. 1C, case 8) and wide FA (Fig. 1B, case 5; Fig. 1D, case 8). Wide FPs among control cases (Fig. 1E, case 1; Fig. 1F, case 3 ) showed normal findings except for the media opacity.

Western blot analysis of AH samples from 10 subjects showed elevated LGR5 expression in PDR patients. Using an LGR5 positive control protein, we evaluated the positive band, validated the western blotting protocol, and analyzed equal concentrations (25 $\mu \mathrm{g} / \mu \mathrm{L})$ of $\mathrm{AH}$ samples. We confirmed that the band appears were more intense in PDR patients (Fig. 2A), which was supported by the quantification results (Fig. 2B). We compared the levels of LGR5 between the control group and PDR group, which revealed a significant increase in the PDR group ( $\mathrm{p}=0.035$, Fig. $2 \mathrm{C}$ ).

To further explore the mechanism of increased LGR5 expression in PDR, we also analyzed the levels of the key members of the Wnt/ $\beta$-catenin signaling pathway, R-spondin-1 (RSPO1), $\beta$-catenin, phosphorylated glycogen synthase kinase-3 $\beta$ (pGSK3 $\beta$ [ser9]), GSK3 $\beta$, cyclin D1 and c-myc, via western blot analysis (Fig. 3). We found that all of the $\mathrm{Wnt} / \beta$-catenin signaling pathway key proteins were increased in AH of the PDR patients group. VEGF, a mediator of retinal pathologic neovascularization, was also increased in $\mathrm{AH}$ of the PDR patients group, as is well known.

In this study, LGR5 was detected in $\mathrm{AH}$ of human eyes for the first time, and was increased in AH of patients with retinal pathologic neovascularization. We also found that the key members of the Wnt/ $\beta$-catenin signaling pathway was increased in AH of PDR patients. LGR5 is known as an adult stem cell marker present as a transmembrane protein; there are two main issues to discuss. First is LGR5 detection in human AH, which is extracellular fluid, and second is the mechanism of LGR5 elevation in pathologic retinal vascularization.

Our results revealed that LGR5 was detected in the extracellular fluid sample. As LGR5 is a membrane protein and has never been found in the extracellular fluid, it is necessary to determine how LGR5 became present in the extracellular fluid. First, based on its known mechanism of action, LGR5 exists not only as a membrane protein, but also as an internalized form in the cytoplasm. The canonical Wnt/ $\beta$-catenin signaling pathway, in which LGR5 acts as an enhancer, is known to be regulated by many regulatory proteins in a variety of manners, including post-translational modification of Wnt proteins, internalization of Wnt receptor complex, regulation of Wnt receptor degradation, and specific ligand-receptor complex formation [19]. LGR5 is a high-affinity receptor for the R-spondin protein family and this R-spondin-LGR5 complex is known to mediate internalization of Wnt receptor complex and Wnt receptor degradation [20-26]. R-spondin-LGR5 signaling contributes to the endocytosis of Wnt receptor complex by promoting the internalization of these components associated with LGR5 [20, 22]. Synder et al. [23] have revealed that LGR5 is internalized rapidly and constitutively into endosomes and to

\section{A $\quad 0.1 \mu g$ Control \\ $\begin{array}{llllllllll}\text { protein } 1 & 2 & 3 & 4 & 5 & 6 & 7 & 8 & 9 & 10\end{array}$}
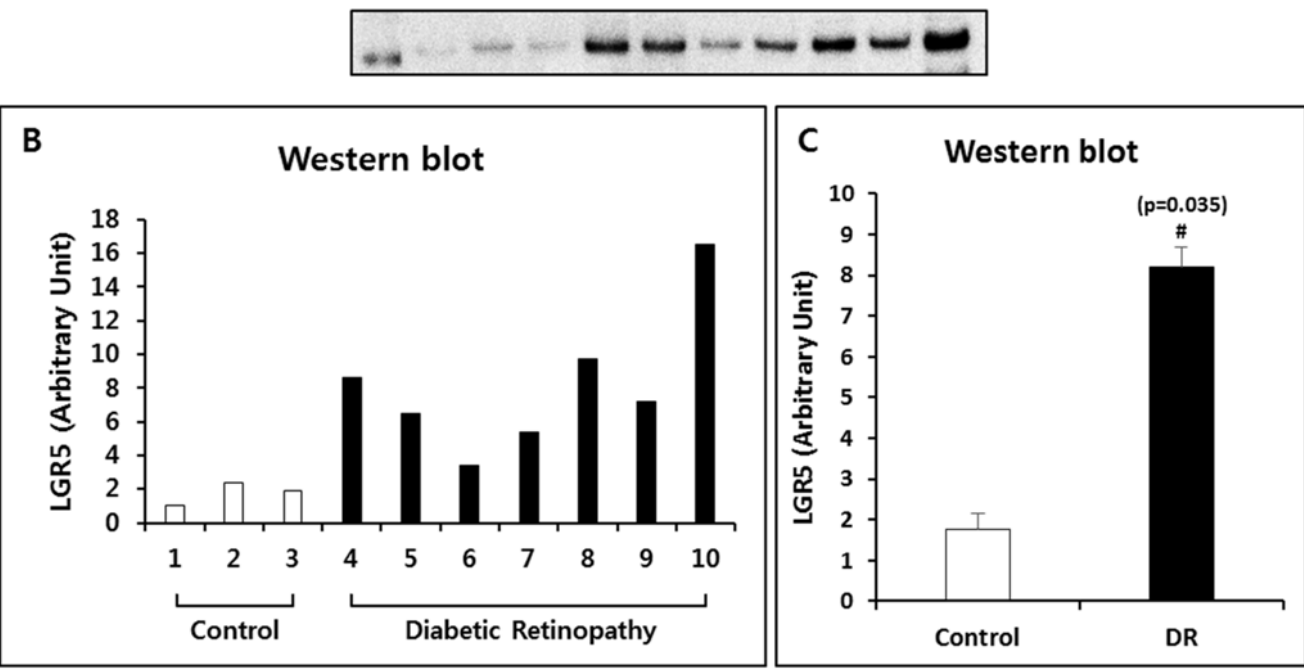

- Primary Ab: LGR5 (monoclonal, 1:200)

- Secondary Ab: Peroxidase-conjugated AffiniPure Donkey Anti-mouse IgG (1:2000)

Fig. 2. Western blot analysis of aqueous humor (AH) samples of control and proliferative diabetic retinopathy (PDR) patients. Equal concentration (25 $\mu \mathrm{g} / \mathrm{ul}$ ) of AH samples and $0.1 \mu \mathrm{g}$ of LGR5 positive control protein were used. LGR5 is elevated in the AH of PDR patients. (A) Western blot bands of LGR5. (B) Quantified levels of LGR5 from western blot. (C) Comparison of LGR5 levels between control group and DR group ( $\left.{ }^{\sharp} \mathrm{p}<0.05\right)$. 

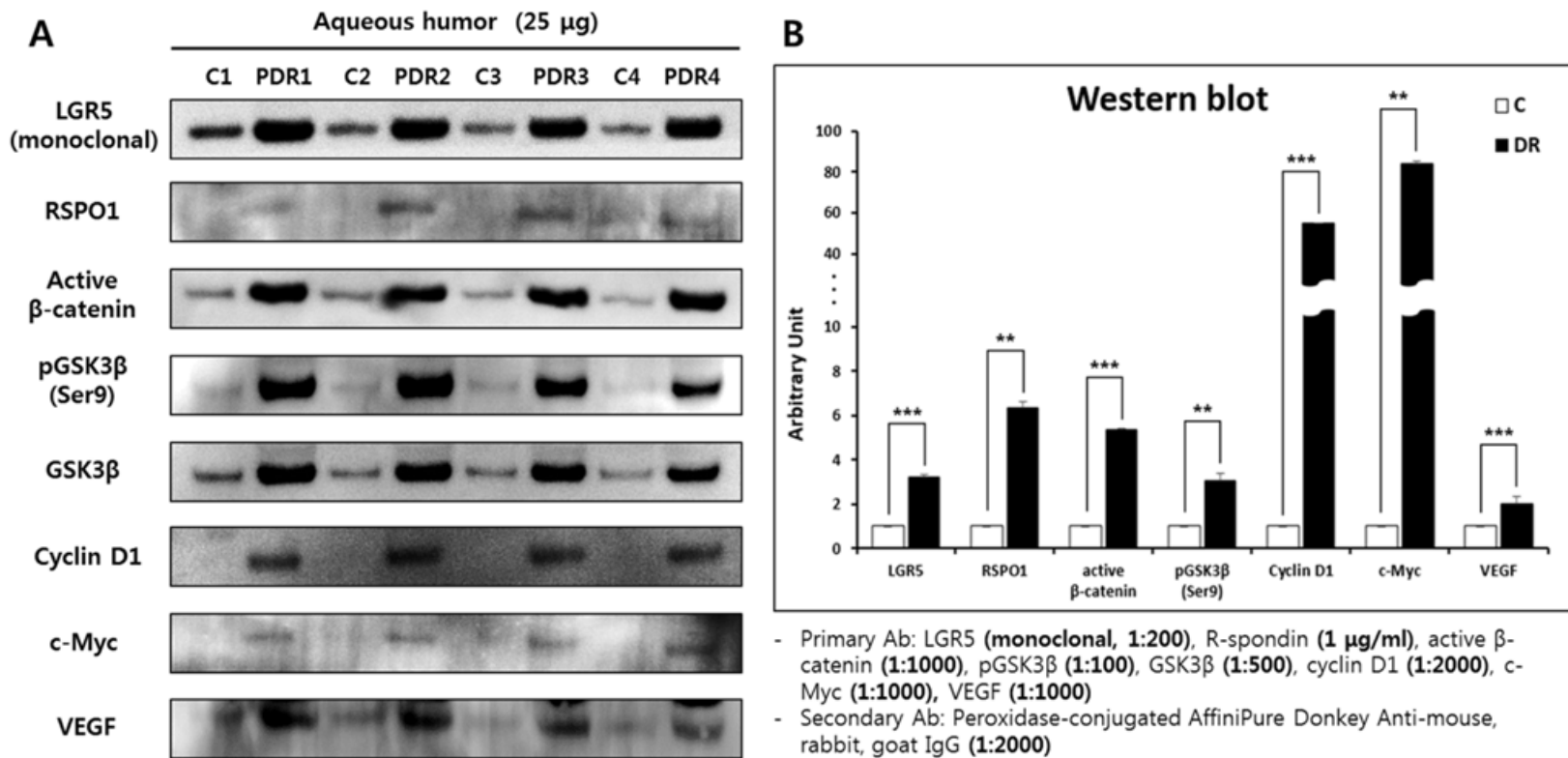

Fig. 3. Western blot analyses of LGR5 and Wnt/ $\beta$-catenin signaling pathway proteins in AH of PDR patients and control subjects. AH samples were obtained from the control and PDR groups, and the mixtures of each group were analyzed via western blot analysis four times. The results showed that the protein levels of LGR5 and key members of the Wnt/ $\beta$-catenin signaling pathway (RSPO1, $\beta$-catenin, pGSK-3 $\beta$ (Ser9), Cyclin D1 and c-Myc) were upregulated in the PDR group. (A) Western blot bands of LGR5 and Wnt/ $\beta$-catenin signaling pathway proteins. (B) Comparison of protein levels between control and DR $\left({ }^{*} \mathrm{p}<0.05,{ }^{* *} \mathrm{p}<0.01,{ }^{* *} \mathrm{p}<0.001\right)$. pGSK-3 $\beta$, phosphorylated glycogen synthase kinase-3 $\beta$; RSPO1, R-spondin-1; VEGF, vascular endothelial growth factor.

the trans-Golgi network under steady-state conditions, and thus LGR5 is predominantly an intracellular protein. While the mechanism by which the LGR5 is released outside the cell is unknown, release may occur via exosomes or ectosomes as a possible mechanism at the specific stage of endosome or from the steady state in the trans-Golgi network. A previous review described that when the membrane proteins are overexpressed, a significant number of receptor molecules are distributed per exosomes [27], and another review summarized the pathway of membrane proteins to shed through exosomes or ectosomes [28]. If LGR5 is secreted through the exosome, the origin of LGR5-containing exosomes may be retinal or other ocular tissues, as in the cases of exosomes derived from retinal pigment epithelium $[29,30]$ or retinal astrocyte [31]. Alternatively, release of LGR5 into the cytoplasm may occur because of cell damage or death. These mechanisms may contribute to LGR5 efflux into the extracellular fluid, and under certain conditions certain mechanisms may become more active.

Several hypotheses may explain the mechanism of LGR5 increase in pathologic retinal neovascularization. It may result from the pathologic neovascularization development process, regenerative process for homeostasis, or retinal cell damage. Wnt/ $\beta$-catenin signaling pathway has been known to play crucial roles in retinal pathologic neovascularization [16, 17]. In animal models of oxygen-induced retinopathy (OIR), expression of Wnt ligand and receptors and Wnt activity were upregulated in pathologic neovascular tufts, and induction of OIR in LRP5 knockout mice showed decreased pathologic neovascularization compared to in wild-type OIR [17]. As LGR5 mediates Wnt/ $\beta$-catenin signaling pathway together with R-spondin, our findings suggest that LGR5 plays a role in retinal pathologic vascularization by regulating the Wnt signaling pathway.

The current dogma explains that differentiated neurons are postmitotic and represent the endpoint of development, which are also true for retinal neurons, and the adult mammalian retina lacks regenerative capacity. However, recently, Chen et al. [14] reported the expression of the adult stem cell marker LGR5 in the retina of adult mice. According to this report, LGR5+ cells are generated late in the retinal developmental stage and are consistent generated throughout the lifetime of mice. Although LGR5+ cells exhibited properties of differentiated amacrine interneurons (amacrine cells), these LGR5 + amacrine cells contributed to retinal cell regeneration (retinal neurons and Müller cells) by dedifferentiation or transdifferentiation, which began in early adulthood and continues with aging. They concluded that LGR5+ amacrine cells serve as endogenous resources for regeneration, namely retinal stem cells, and may contribute to maintaining the homeostasis of retina throughout the lifetime of the animal. Based on these findings, our results suggest that LGR5 is expressed to maintain homeostasis, 
this action is more active in the PDR, and LGR5 expression is further increased in the PDR.

There are several limitations in this study. First, this was a pilot study with a small number of samples. Patients were all PDR, and the patients could not be classified according to their characteristics because of the small population. However, because this study was a preliminary study, we did not include the non-proliferative stage of diabetic retinopathy and included only the PDR group for a clear comparison. Furthermore, there were some young diabetic patients who presented severe PDR, and such patients were also selected for clear comparison in this study. On the other hand, cataract patients who need surgery are mostly elderly. Therefore, we could not match the ages of the two groups. Second, as this study used a cross-sectional design, it was not possible to compare the changes in aqueous LGR5 level over time or before and after treatment. A longitudinal study is needed to investigate changes in aqueous LGR5 levels over time, relationship between aqueous LGR5 level and treatment response. Third, the protein amount of the AH sample obtained from a single sampling procedure was very small, so we could not carry out multiple analyses simultaneously with a single AH sample. Thus, we could only perform western blot analysis of LGR5 with AH samples at the first time. For further analyses of $\mathrm{Wnt} / \beta$-catenin signaling pathway proteins, we used the mixture of several samples in each group. Finally, in this study, only the results of ophthalmologic examination and analysis of human $\mathrm{AH}$ were presented. As this study confirmed the detection of LGR5 in human AH, studies to reveal the mechanisms of LGR5 detection in AH and LGR5 increase in pathologic retinal NV should be carried out (animal studies, etc.).

In conclusion, we detected LGR5 in human AH for the first time. As LGR5 is a stem cell marker, which reflects regenerative capacity, this may be a good platform for investigating cell replacementbased therapy. Our results suggest that LGR 5 plays a role in retinal NV development in PDR, which can be used as a novel biomarker of retinal neovascularization and a target protein for preventing NV. Further studies using more relevant animal models and human samples are needed to confirm the role and clinical significance of LGR5.

\section{ACKNOWLEDGEMENTS}

This research was supported by Basic Science Research Program through the National Research Foundation of Korea funded by the Ministry of Education (NRF-2017R1D1A1B03030905, NRF2017R1D1A1B03031934 and NRF-2015R1D1A1A01060644).

\section{REFERENCES}

1. Hsu SY, Liang SG, Hsueh AJ (1998) Characterization of two LGR genes homologous to gonadotropin and thyrotropin receptors with extracellular leucine-rich repeats and a $G$ protein-coupled, seven-transmembrane region. Mol Endocrinol 12:1830-1845.

2. McDonald T, Wang R, Bailey W, Xie G, Chen F, Caskey CT, Liu Q (1998) Identification and cloning of an orphan G protein-coupled receptor of the glycoprotein hormone receptor subfamily. Biochem Biophys Res Commun 247:266-270.

3. Barker N, Huch M, Kujala P, van de Wetering M, Snippert HJ, van Es JH, Sato T, Stange DE, Begthel H, van den Born M, Danenberg E, van den Brink S, Korving J, Abo A, Peters PJ, Wright N, Poulsom R, Clevers H (2010) Lgr5(+ve) stem cells drive self-renewal in the stomach and build long-lived gastric units in vitro. Cell Stem Cell 6:25-36.

4. Barker N, van Es JH, Kuipers J, Kujala P, van den Born M, Cozijnsen M, Haegebarth A, Korving J, Begthel H, Peters PJ, Clevers H (2007) Identification of stem cells in small intestine and colon by marker gene Lgr5. Nature 449:1003-1007.

5. Huch M, Dorrell C, Boj SF, van Es JH, Li VS, van de Wetering M, Sato T, Hamer K, Sasaki N, Finegold MJ, Haft A, Vries RG, Grompe M, Clevers H (2013) In vitro expansion of single Lgr5+ liver stem cells induced by Wnt-driven regeneration. Nature 494:247-250.

6. Huch M, Bonfanti P, Boj SF, Sato T, Loomans CJ, van de Wetering M, Sojoodi M, Li VS, Schuijers J, Gracanin A, Ringnalda F, Begthel H, Hamer K, Mulder J, van Es JH, de Koning E, Vries RG, Heimberg H, Clevers H (2013) Unlimited in vitro expansion of adult bi-potent pancreas progenitors through the Lgr5/R-spondin axis. EMBO J 32:2708-2721.

7. Barker N, Rookmaaker MB, Kujala P, Ng A, Leushacke M, Snippert H, van de Wetering M, Tan S, Van Es JH, Huch M, Poulsom R, Verhaar MC, Peters PJ, Clevers H (2012) Lgr5(+ve) stem/progenitor cells contribute to nephron formation during kidney development. Cell Reports 2:540-552.

8. Ng A, Tan S, Singh G, Rizk P, Swathi Y, Tan TZ, Huang RY, Leushacke M, Barker N (2014) Lgr5 marks stem/progenitor cells in ovary and tubal epithelia. Nat Cell Biol 16:745-757.

9. Shi F, Kempfle JS, Edge AS (2012) Wnt-responsive Lgr5expressing stem cells are hair cell progenitors in the cochlea. J Neurosci 32:9639-9648.

10. Plaks V, Brenot A, Lawson DA, Linnemann JR, Van Kappel EC, Wong KC, de Sauvage F, Klein OD, Werb Z (2013) Lgr5expressing cells are sufficient and necessary for postnatal mammary gland organogenesis. Cell Reports 3:70-78. 
11. Hirata-Tominaga K, Nakamura T, Okumura N, Kawasaki S, Kay EP, Barrandon Y, Koizumi N, Kinoshita S (2013) Corneal endothelial cell fate is maintained by LGR5 through the regulation of hedgehog and Wnt pathway. Stem Cells 31:13961407.

12. Li DQ, Wang Z, Yoon KC, Bian F (2014) Characterization, isolation, expansion and clinical therapy of human corneal epithelial stem/progenitor cells. J Stem Cells 9:79-91.

13. Brzeszczynska J, Ramaesh K, Dhillon B, Ross JA (2012) Molecular profile of organ culture-stored corneal epithelium: LGR5 is a potential new phenotypic marker of residual human corneal limbal epithelial stem cells. Int J Mol Med 29:871-876.

14. Chen M, Tian S, Glasgow NG, Gibson G, Yang X, Shiber CE, Funderburgh J, Watkins S, Johnson JW, Schuman JS, Liu H (2015) Lgr5+ amacrine cells possess regenerative potential in the retina of adult mice. Aging Cell 14:635-643.

15. Sukhdeo K, Koch CE, Miller TE, Zhou H, Rivera M, Yan K, Cepko CL, Lathia JD, Rich JN (2014) The Lgr5 transgene is expressed specifically in glycinergic amacrine cells in the mouse retina. Exp Eye Res 119:106-110.

16. Drenser KA (2016) Wnt signaling pathway in retinal vascularization. Eye Brain 8:141-146.

17. Chen J, Stahl A, Krah NM, Seaward MR, Dennison RJ, Sapieha P, Hua J, Hatton CJ, Juan AM, Aderman CM, Willett KL, Guerin KI, Mammoto A, Campbell M, Smith LE (2011) Wnt signaling mediates pathological vascular growth in proliferative retinopathy. Circulation 124:1871-1881.

18. Niehrs C (2012) The complex world of WNT receptor signalling. Nat Rev Mol Cell Biol 13:767-779.

19. Jiang X, Cong F (2016) Novel regulation of Wnt signaling at the proximal membrane level. Trends Biochem Sci 41:773783.

20. Glinka A, Dolde C, Kirsch N, Huang YL, Kazanskaya O, Ingelfinger D, Boutros M, Cruciat CM, Niehrs C (2011) LGR4 and LGR5 are R-spondin receptors mediating Wnt/ $\beta$-catenin and Wnt/PCP signalling. EMBO Rep 12:1055-1061.
21. Hao HX, Xie Y, Zhang Y, Charlat O, Oster E, Avello M, Lei H, Mickanin C, Liu D, Ruffner H, Mao X, Ma Q, Zamponi R, Bouwmeester T, Finan PM, Kirschner MW, Porter JA, Serluca FC, Cong F (2012) ZNRF3 promotes Wnt receptor turnover in an R-spondin-sensitive manner. Nature 485:195-200.

22. Carmon KS, Lin Q, Gong X, Thomas A, Liu Q (2012) LGR5 interacts and cointernalizes with Wnt receptors to modulate Wnt/ $\beta$-catenin signaling. Mol Cell Biol 32:2054-2064.

23. Snyder JC, Rochelle LK, Lyerly HK, Caron MG, Barak LS (2013) Constitutive internalization of the leucine-rich G protein-coupled receptor-5 (LGR5) to the trans-Golgi network. J Biol Chem 288:10286-10297.

24. Blitzer JT, Nusse R (2006) A critical role for endocytosis in Wnt signaling. BMC Cell Biol 7:28.

25. Bryja V, Cajánek L, Grahn A, Schulte G (2007) Inhibition of endocytosis blocks Wnt signalling to $\beta$-catenin by promoting dishevelled degradation. Acta Physiol (Oxf) 190:55-61.

26. Seto ES, Bellen HJ (2006) Internalization is required for proper Wingless signaling in Drosophila melanogaster. J Cell Biol 173:95-106.

27. Keller S, Sanderson MP, Stoeck A, Altevogt P (2006) Exosomes: from biogenesis and secretion to biological function. Immunol Lett 107:102-108.

28. Cocucci E, Meldolesi J (2015) Ectosomes and exosomes: shedding the confusion between extracellular vesicles. Trends Cell Biol 25:364-372.

29. Locke CJ, Congrove NR, Dismuke WM, Bowen TJ, Stamer WD, McKay BS (2014) Controlled exosome release from the retinal pigment epithelium in situ. Exp Eye Res 129:1-4.

30. Calebiro D, Nikolaev VO, Persani L, Lohse MJ (2010) Signaling by internalized G-protein-coupled receptors. Trends Pharmacol Sci 31:221-228.

31. Hajrasouliha AR, Jiang G, Lu Q, Lu H, Kaplan HJ, Zhang HG, Shao H (2013) Exosomes from retinal astrocytes contain antiangiogenic components that inhibit laser-induced choroidal neovascularization. J Biol Chem 288:28058-28067. 